\title{
A IMPORTÂNCIA DO SISTEMA TOYOTA DE PRODUÇÃO PARA O DESENVOLVIMENTO DE EMPRESAS DE SEGUIMENTOS DIVERSOS

\author{
Generthon Silva Aniceto ${ }^{1}$
} \\ Carlos Marcelo de Siqueira ${ }^{2}$ \\ Danillo Lopes Nunes ${ }^{3}$
}

\begin{abstract}
Resumo: A competitividade do mercado tem exigido maior dedicação e performance das empresas na hora de gerir seus recursos, e para isto é necessário que sempre se busque maneiras de melhorar o processo tornando-o mais enxuto possível. Neste artigo será abordado na forma de revisão bibliográfica os princípios e benefícios da adoção do Lean Manufacturing, ressaltando como a aplicação desta metodologia em empresas de seguimentos variados pode impulsiona-las para uma maior competitividade no mercado. Para isto será apresentado uma contextualização histórica da origem do Lean Manufacturing e suas principais ferramentas. Em seguida o enfoque é dado a estudos de caso já realizados, evidenciando a evolução das empresas após a aplicação da metodologia Lean. Mediante os estudos realizados, acredita-se que a implementação de métodos ligados ao Lean Manufacturing pode trazer vantagens competitivas mesmo em empresas de ramos produtivos diferentes.

Palavras-chave: Lean Manufacturing; Eliminação de desperdícios; Empresas de seguimentos diversos; Competitividade.
\end{abstract}

\footnotetext{
${ }^{1}$ Engenharia de produção/FEPI - Centro Universitário de Itajubá, Brasil. E-Mail: generthon@gmail.com.

2 Engenharia de produção/FEPI - Centro Universitário de Itajubá, Brasil. E-Mail: cmsiqueira94@gmail.com.

${ }^{3}$ Engenharia de produção/FEPI - Centro Universitário de Itajubá, Brasil. E-Mail: nunes.prod@gmail.com.
} 